\title{
Public procurement of winter road maintenance services based on EU procurement directive - Lessons from Sweden
}

\author{
Adel Abdi ${ }^{1}$, Hans Lind ${ }^{2}$, Björn Birgisson ${ }^{1}$ \\ ${ }^{1}$ Royal Institute of Technology - KTH, Department of Transport Science, Division of Highway and Railway Engineering, Stockholm, \\ Sweden \\ ${ }^{2}$ Royal Institute of Technology - KTH, Department of Real Estate and Construction Management, Division of Building and Real Estate \\ Economics, Stockholm, Sweden
}

Email address:

adel.abdi@abe.kth.se (A. Abdi), hans.lind@abe.kth.se (H. Lind), bjornbir@kth.se (B. Birgisson)

\section{To cite this article:}

Adel Abdi, Hans Lind, Björn Birgisson. Public Procurement of Winter Road Maintenance Services Based on EU Procurement Directive - Lessons from Sweden. Journal of Investment and Management. Vol. 2, No. 4, 2013, pp. 70-86. doi: 10.11648/j.jim.20130204.11

\begin{abstract}
Public procurement of road maintenance services, particularly in cold regions is not an easy task in order to satisfy road-users during winter. Road-users' dissatisfaction, complaint and pressure can usually be considered as major factors for having more accessible and safe roads during winter. These pressures have contributed and led to an increasing critical approach focusing on public procurement of these services after some harsh winters in the recent years in Sweden with traffic disruption and delay as consequence i.e. an increasing focus on the way in which the Swedish state authorities and local governments procure winter road maintenance services. The present study which is part of a larger research project investigating efficient winter road maintenance through procurement, tendering and contract aimed at extending this knowledge base with regard to procurement and socioeconomic factors with focus on the winter maintenance of the Swedish road network. The study reveals that even the Swedish winter road maintenance services are procured and outsourced in accordance with EU directive and public procurement rules transposed into the Swedish act on public procurement, the act has been interpreted in a manner that all the process has led to great dissatisfaction of end-users during winter due to improper bundling of winter related services. The lack of economic motivation in current contracts concerning winter road maintenance in the form of incentives has led to an inefficient performance of winter road measures. The study suggests a number of proposals in order to make forthcoming contracts more effective through proper bundling of winter services and create incentives for contractors to improve the performance of winter road maintenance services.
\end{abstract}

Keywords: Public Procurement, Procurement Legislation, Tender, Contract, Incentives, Bundling Services

\section{Introduction}

\subsection{General Background}

Governments normally aim to create an affordable road network and to have as many roads as possible fully maintained to an acceptable standard [1]. Winter road maintenance in cold regions requires that roads are kept free from obstructions by snow and ice. This is a very extensive, important, difficult and therefore expensive work. Extensive, because winter is a substantial part of the year, important because sever restrictions on accessibility in winter would have adverse social effects, and expensive due to the large amount of work to be done, often at inconvenient hours and with high material consumption e.g. salt and sand. It is difficult due to the frequent and sudden changes in weather with potential for highly adverse effects and the need for immediate simultaneous actions over large parts of the road network [2].

To increase traffic safety and accessibility for road-users in the winter a well-planned procurement procedure and a well-structured contract with entrepreneurs are required in order to achieve high level of winter maintenance services. When procuring these services, the high importance of winter maintenance has to be taken into consideration very carefully in the inquiry-specification since ambiguities and oversights in the contract can obstruct or delay winter road maintenance performance, and thereby generate difficulties in obtaining the appropriate service level [2].

During the past two decades, maintenance of road 
infrastructure including winter maintenance in the most European countries and North America has contractually undergone very vast and radical changes. There are a number of reasons behind the changes. As [3] describes one important reason to these changes is the re-organising and general renewal of the public sector. This implies that maintenance of these infrastructures have gone from more traditional in-house model over to more outsourcing model in order to create a more competitive procurement and bidding environment within construction industry to get more value for money. Today, the public sector in many countries has outsourced all its own production and service activities i.e. all the products and services have been put out to tender.

Since road maintenance services including winter maintenance have been put out to competitive procurement and contract, some road authorities encountered problems in terms of productivity, service quality and hidden extra costs etc. As stated in [1], moving over to competitive procurement makes the need for standards to be more explicit and making these very precise can reduce flexibility and be counterproductive.

In Sweden, winter road maintenance integrated in an allyear-round maintenance package, is implemented through public procurement under ownership of state authorities and local governments such as Swedish Transport Administration (STA) and municipalities. Given the complexity of winter road maintenance, procurement of these services publicly is not an easy task, particularly combined with the other road maintenance purposes without any correlation to winter maintenance activities.

\subsection{Objectives and Method}

As our earlier studies [4] have shown there is a widespread dissatisfaction with the public procurement and contracting of winter road maintenance in Sweden. The study therefore aims further to analyse two central issues in the procurement process based on the Swedish act on public procurement. These two issues are:

- Advantages and disadvantages in bundling winter road maintenance activities with other separately procured winter related services in one single contract

- How to create incentives in a complex situation where it is difficult in a number of situations to clarify in advance what should be done

The objective of this study is further to investigate and find how the Swedish procurement laws have been influenced by European Union's (EU) procurement directive and rules since Sweden entered to the EU. The study finally aims to propose possible improvement of current procurement method thereby a more functional contract.

The methodology for this study includes a review of the most relevant theories concerning procurement methods in public sector within infrastructure/construction maintenance. The study is further followed by a number of empirical investigations such as semi-structured interviews and electronic questionnaire survey both domestically and internationally. A more detailed methodology of the study is presented in section five.

\subsection{Structure of the Article}

This paper is organised into seven sections. Section two is a discussion of the theoretical framework through highlighting some key factors in the procurement context. The legal framework in public procurement is presented in section three continued by a short review of the current debate on public procurement in section four. Section five is presentation of method and collected material through a number of empirical investigations followed by description of findings. Analysis of findings is highlighted in section six with proposal to improvement of current procurement method. The paper ends with conclusions in section seven.

\section{Theoretical Framework}

When planning to procure products or services as [5] claims, by using some appropriate sourcing strategies, client organisations can organise their procurement process. The sourcing strategies according to [5] can appear in some sourcing or supply structures namely; single, multiple, delegated and parallel. The application of each structure depends directly on the procurement organisations' needs. Applying single sourcing as $[5,6]$ state can affect the competitive market and reduce the number of service providers. This implies that procuring through single sourcing gives the client organisations increased possibility to select only one supplier/contractor they want despite of several available contractors of same services on the market The structure in Sweden is that there is a "single-sourcing" contract for each region during a certain time, but the procurement in the different regions is made independently from each other. There procurement should not take into account the effect on the future competitiveness of the market but choose the supplier that fulfils the criteria best in the specific procurement contract.

\subsection{Why Products or Services Should Be Bundled}

Since the idea of bundling products or services received attention during 60's the economists viewed price bundling as alternative technique for a monopolist to introduce price discrimination. When a strong focus was placed on customer relationship during 90's, bundling received even more attention in the marketing literature [7].

While [8] claims that bundling is pervasive in today's market and generally lacks definition, then [6] defines bundling as the sale of two or more separate products in one package. In this context, they define the term separate products as products for which separate markets exist. Bundling is also defined by [9] as selling two or more products or services "in a single package for a special price". 
Reference [10] gives an overview of the theories behind the choice whether to bundle services or not in the context of whether construction and maintenance should be bundled as in a Public Private Partnership-project (PPPproject). The literature points to several possible arguments for bundling as follow:

- Information and learning aspects: The company that produces e.g. a copy machine or a car knows more about how the product works and can therefore be more efficient in repairing and maintaining it. More generally it may be the case that when you do activity $A$, you learn something that reduces the cost of carrying out activity $B$. By bundling $A$ and $B$ the total cost, including learning costs, can be reduced

- Economies of scale: By bundling two activities; staff, machinery and equipment may be used in a more efficient way if e.g. the two activities are carried out during different time periods

- Contractual design: If activity $A$ is a precondition for activity $B$ and the quality of activity $B$ is easier to observe, it might from contractual aspects be rational to bundle activity $A$ and $B$ as activity $A$, then $A$ and $B$ do not need to be evaluated separately

- Direct transaction costs: If each procurement has some fixed costs then bundling two activities would reduce these direct transaction costs

But the literature also points to cases where bundling primarily is done to reduce competition. As [11] states, improper contract bundling may generate a number of harmful impacts to construction companies and the governments, due to risk for reduction or elimination of bidder interest and the level of competition for procurement. A famous case in software industry is where Microsoft tried to integrate its web-browser into the operating system thereby making it more difficult for the consumers to choose other browsers. Bundling of operation and maintenance can also reduce competition as few companies may be able to deliver the integrated service, and as the transaction cost to form a new joint venture for the specific contract may be high.

Reference [12] points to a number of claims in this connection such as those clients that bundle related services are able to reduce the personnel needed to provide the services through the use of multi-skills and the personnel that set up and manage contracts and pay invoices. The contractors are also able to reduce the personnel in contract management and other activities associated with transacting with clients that generally are paid by the clients. Reference [12] also highlights other cost reducing sources than personnel reduction in bundle service contract such as materials, equipment and logistic transportation services. Procurement of related services separately makes the client coordinate all efforts or run the risk of a bad outcome. When clients procure and contract related services bundled can the performance quality, flexibility and responsiveness be improved by the contract-awarded contractors.

\subsection{Incentives in Contract}

This is of course a very complex issue (see [13] for a classic overview of the main issues) but one can identify two general ways of getting an agent to do what the principal wants the agent to do.

- A complete verifiable contract with sanctions specified in the contract. The contract says that the agent should do $A$ and get paid $P$, but if the agent does not deliver $A$ but instead $A$, then the payment will be reduced with a pre-specified amount and the payment will not be $P$

- If the principal realises that it will be very difficult to specify in advance exactly what should be done, and also if the specific characteristics that the object should have, (e.g. friction on a road during certain weather conditions) are difficult to describe, then another incentive models are necessary. On the labour market career-possibilities can create incentives in such situations and on many other markets the strongest incentives are future business opportunities. If the Principal is not satisfied it may not be possible to go to court and get a sanction as the contract may not be so exact and the circumstances are not easy to observe for a third party, but the Principal can go to another company the next period if they are not happy (satisfied) with the performance of the agent

\subsection{Research in Public Procurement}

According to [14] the aim of procurement should be to achieving effectiveness and efficiency in terms of obtaining the lowest price for goods and services that meets the client's requirements in a way that is rapid and routine for both client and supplier in the case of contracting.

Assuming a more strategic focus, [5] states that the basic reason for procurement of products and services depends on a number of pressures placed upon it from a competitive perspective. These pressures could be political which force changes in both supply and the structure of industries e.g. privatisation of public sector. It could also be economic pressures that force organisations to examine alternative set of practices in their supply chain management. It may even be social pressures in order to develop procurement professions and it can finally be technological pressures in terms of advances in information technology that have raised the visibility of the supply process in the companies. These pressures on the procurement are likely for revealing how the costs for contractors work, but according to [15] the procurement problems practically seem to be more than revealing a supplier's cost function i.e. it is about other challenges a client faces. These challenges could e.g. be what a client exactly wants to procure and the way to convey the needs to the possible contractors and to find potential remuneration models that should be profitable for both client and contractor.

As [15] studied, both public and private sector organisations are similarly engaged in procuring similar 
products and services but the way in which the services are procured dramatically differs between this two sectors. In many countries like USA, Sweden, Norway and Finland the public sector is often forced by rules to apply a certain payment method, e.g. fixed-price or unit price and/or occasionally a combination of both methods, when procuring goods or services. The public sector may also have to follow certain procedures for choosing the contractor, and it may be possible for the contractor to have the procedure reviewed by a higher authority. Differed from the public sector as [15] studied the private sector has fewer constraints while procuring and it is due to the added flexibility in this sector.

To create flexibility and thereby incentives in a contract when procuring a project (the project can even be goods and/or services) a client expects that the project generates a value when it is performed. As [15]'s research shows, the contractor performs the project only according to the minimum agreed standard if there is a pre-specified price with a fixed-price contract. This implies that the potential adaptions (authors' interpretation: alteration and additional work) have to be negotiated separately if necessary. As discussed in $[16,17]$ a partnering contract may be one way to create flexibility also in a public sector contract.

\section{Procurement Framework}

\subsection{The Legal Framework}

In order to make the construction industry more competitive and effective, the EU parliament has made a decision and established legislation in this area. Every member state has to follow the legislation when procuring any projects within this area. When carrying out all procurements within EU, a number of principles for public procurement a so-called Fundamental EU procurement principles have to be taken into consideration. This implies that the free movement of people, goods, services and capital within EU are guaranteed. Public procurement principles must also be observed in terms of nondiscrimination, equal treatment, proportionality, transparency and mutual recognition when procuring services publicly [18].

In order to ensure a correct and objective procurement in accordance with the procurement laws and regulations in the Nordic countries and the European Union/European Economic Association (EU/EEA) several transport organisations in Scandinavia decided to establish a joint qualification system in 1998 [19]. The qualification system namely; Trans $Q$ is a web based transport supplier qualification register that is used by the Nordic transportation organisations in order to check and approve suppliers that may meet the clients' entrance requirements when procuring products and services. By using the Trans Q system transport clients are able to make a list over the qualified suppliers/contractors that want to participate in bidding and thereby to shorten the procurement process.
The system is even a gateway for contractors that fulfil the clients' requirements and seek for contract to participate in tendering [19].

\subsection{Procurement Procedure at STA}

For a long time construction, operation and maintenance of the Swedish road and railway network had been the responsibility of the former Swedish Road Administration and Swedish Railway Administration. The maintenance tasks had been performing in-house by these two authorities.

In 1992, The Act on Public Procurement [20] was introduced by the Swedish government in order to create good condition for competition and transparency in the public procurement area regulating all public expenditure $[2,21]$. Since the early 90 's the operation and maintenance of these state infrastructures has been performed by public procurement following the Act. This means that these services are performed by public or private contractors after a legal procurement process.

In 2008, in order to synchronise the Swedish Act on Public Procurement with the EU directive in public procurement, some changes in the Act were carried out. The old act from 1992 was replaced by two new acts [22] namely; the general act on public procurement that covers most sectors (e.g. road sector) and the act on procurement in the water, energy, transport and postal services sector and the utilities sector concerning railway-related operations.

In order to create a more efficient and unified infrastructure authority, according to a decision made by the Swedish government, the two above named agencies were merged with each other on $1^{\text {th }}$ of April 2010 to build the new transport authority i.e. STA that currently is responsible for the construction, operation and maintenance of all state owned roads and railways. The new transport authority as the largest public contracting organisation in Sweden has tried to improve the previous procurement model to a more functional one. Winter road maintenance as a part of the annual highway maintenance services is inclusively and publicly procured by STA in accordance with the general sector act [18].

Since $1^{\text {th }}$ of April 2010, the STA's new policy is to go forward to being a more pure administrative client organisation and transfer, and completely outsource all design, construction, operation and maintenance activities including winter maintenance of Swedish road and railway infrastructures through public procurement in order to make the activities more efficient and cost effective. The argument behind the idea has been that performing more activities by outsourcing through general contract/turnkey with fixed-price increases the pace of innovation and improves productivity in the construction industry and creates a situation that allows the client organisation to get more road and railway for the money.

In order to procure road maintenance services including winter maintenance, a so-called threshold value is applied. It implies that different procurement regulations and 
procedures are selected depending on the value of the procurement i.e. whether it is under or over certain threshold values. The threshold values are as table 1 shows.
These values are revised every two years by the Swedish government [23].

Table1. Current threshold values [18, 23]

\begin{tabular}{lll}
\hline Threshold values for procurement of goods and services in accordance with the Swedish public procurement act \\
\hline Instances/bodies & EURO & SEK* \\
\hline Government authorities. & 130000 & 1233401 \\
Other procuring authorities (e.g. county councils, municipalities, public utility companies). & 200000 & 1897540 \\
Building contractors (all procuring authorities). & 5000000 & 47438500 \\
\hline * SEK (Swedish Kronor) & & \\
\hline
\end{tabular}

The procurement process starts with the identification of the needs for performance of road services in order to keep the state roads accessible, available and safe for road-users around the year. The needs are regularly discussed, collected and defined in a so-called inquiry specification. The inquiry specification is a collective documentation that consists of several additional documents and describes all the road maintenance needs to be procured including winter services. The inquiry specification includes among other things procurement and administrative regulations, technical specifications of requirements, description of standards and a proposal to contract. The next step is to advertise the procurement. All procurements are advertised both in a database and on the website of STA which are publicly accessible to all tenderers both nationally and internationally.

When procuring in accordance with the Swedish Act on Public procurement, STA uses the prequalifying system Trans $Q$ (previously mentioned). All services or the contract works that will be procured are specified in the system. A detailed inquiry specification specifies the demands and requirements that must be met by the suppliers/contractors. This procurement specification is then published on the STA's procurement system; Complete Tender Management (CTM). For every procurement, a deadline for tender submission is given in procurement specification for submission of tenders. If a tender is submitted too late after the deadline it may not be included for further check and evaluation. After the deadline all the submitted tenders will be opened and evaluated in accordance with the criteria set out in the inquiry specification. According to STA, it is based on either the lowest price or the most economically advantageous tender. Which one of the alternatives will be applied must be specified in the procurement specifications. A notification is sent out to all the tenderers setting out which contractor(s) has (have) been awarded the contract. When awarding contracts on the basis of the most economically advantageous tender the quality aspects should be taken into account not just what is cheapest. The contract can be signed at the earliest ten days after the award notification has been sent. During these ten days, the other bidders may appeal.

If there is not any appeals the contract is signed with the winning contractor but in case of appeals STA cannot sign the contract with the contractor until the Swedish Administrative Court considers and makes its decision whether the procurement is correct or not. This means that overall timetable will be affected and may be delayed.

If tax laws, safety regulations, working conditions or health and safety laws are not followed since a contract is signed, the client is entitled to cancel the on-going contract with the supplier/contractor. In such cases there are accepted agreements to cancel a contract but it must be ensured that the notice period is long enough to start a new procurement process before the previous contract is terminated. This normally takes between 14 and 18 months including establishment time for the new entrepreneur. How the procurement of road maintenance services is carried out, is illustrated in Fig.1.

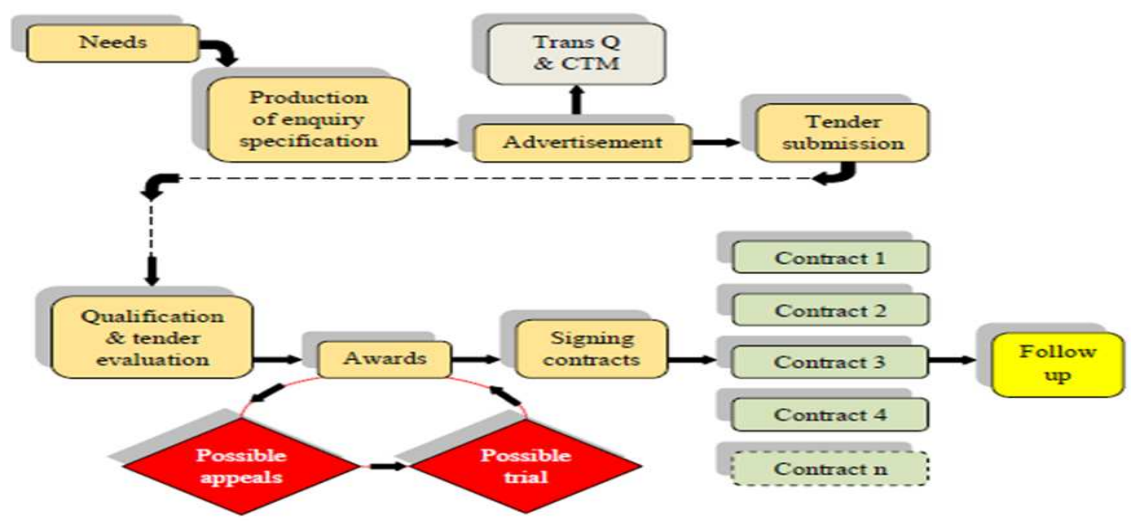

Figure 1. Flow-chart of the procurement procedure at STA 


\section{Current Debate on Public Procurement}

As mentioned earlier within European Union, public procurement has nowadays become one of the fundamental columns in construction industry but it is regulated by the European Directive 2004/18/EC [24] and has to be transposed into every member state's public procurement laws. How the laws of public procurement work is hotly debated in a number of countries. In this connection two recently published reports from UK and Sweden were selected to be highlighted.

\section{1. $U K$}

In May 2011the British government launched a new Construction Strategy to reduce the construction costs by up to $20 \%$. This had to be achieved over the mandate of the current parliament. This new construction strategy brought a hot debate in the construction industry as a consequence.

A report published by [25] shows that the construction sector is a major part of the UK's economy and the public sector is the construction's largest client. In the context of the construction strategy the same report reveals the lack of expertise in the public sector. As long as the clients do not know what it is they want, how much they need to pay for it and do not know how to select suppliers that can deliver the best project, the efficiency and value for money is hampered. The report argues for more flexible approaches to achieve the $20 \%$ saving in construction costs i.e. the bidders should be selected against a range of criteria, a socalled balanced scorecard. Projects (supplies or services) must be procured on the basis of integrated teams including designers, contractors, project managers, facilities managers with the ability of teams to work together. Selection of an integrated team must not be made on the basis of lowest price but on the basis of a more balanced scorecard that will be marking the bid against specified criteria of which sustainability should be one [25].

Another aspect that is debated in the UK is the problems of EU procurement rules. How too burdensome rules and regulations have stifled and still stifling the efficiency, increase the costs and reduce the competition by cutting out the small firms has been repeatedly highlighted in the UK. Among the risk-averse clients there is a so-called tick-box mentality that often overloads prequalification questionnaires with questions that have no relevance.

As the report shows there is a perception that the public sector's tick-box mentality in the UK is often amplified by the EU procurement rules although there have been witnesses that considered that it was the UK's overzealous interpretation of the EU procurement rules not so much the rules themselves.

Some contractors in the UK perceive that the public sector approach to the procurement process actually stops the ability of people to get around the table and engage with what they really want to achieve.

One area where UK's public sector procurement has been changing over the past decades is in the use of framework agreements, whereby bidders are chosen to work with clients over a certain period e.g. four or more years. The bidder may be one of several who then have to go through mini bids to win actual projects, or the sole framework supplier who then does all the work. Another development has seen the likes of local authorities bundling contracts together [25].

The report summarises some recommendations for an improved procurement process as follow:

- Collaborative procurement of framework agreement provides substantial saving to the public sector i.e. saving money and procurement time on every project

- An intelligent application of the European Procurement Directive should be seen. EU procurement rules must not be interpreted to prevent procurement, which gives proper focus to an underlying basis of trust and a collaborative approach

- $\quad$ Public sector clients need better guidance to help prevent them from over-interpreting EU procurement rules, which can create barriers to entry and a tick-box mentality. Public sector clients need to feel confident that, should they act to make their decision on more "value driven" basis, they will subsequently not be subject to unreasonable challenges

\subsection{Sweden}

In autumn 2010, the Swedish Government's procurement committee was assigned to evaluate the procurement rules from an economic and socio-political perspective and review the system for collecting procurement statistics and which statistics should be collected. The government's motives were several, including getting a basis for the then forthcoming review of the EU public procurement directive but also to consider the widespread criticism of current procurement legislation and its application.

After an extensive outward/extrovert investigation on the criticism from the public sector, companies, academics/researchers, stakeholder organisations and others, in March 2013 the procurement committee published a final report as the most recent/latest government report in Sweden by the title Good business - a strategy for sustainable public procurement [26]. The report can be summarised as follows:

The public procurement has a clear preponderance towards application of the law. Other important aspects of the good business have been neglected.

The public procurement suffers from lack of leadership and strategic perspective. Both the parliament and the government seem to lack a cohesive approach to the significance/importance of the public procurement for key 
parts of the society's service. They have not utilised the complete potential of the procurement as a political governance tool or for managing common resources.

Although the public procurement often concerns the core of welfare, the head of authorities pay too little attention to it. Many authorities have no or an unclear strategy for their public procurement.

There is a significant knowledge deficiency in this area. Due to poor statistics there is uncertainty about how large sums the turnover is in public procurement in Sweden. Furthermore, there are knowledge gaps in competitive situations in the various markets i.e. the extent to which firms of different sizes are involved in procurement, what are to be procured etc. All this complicates the deeper analysis of public procurement. The poor statistics is an important reason for the difficulties in calculating the impact of the environmental and social requirements.

The legislation and its application are perceived as cumbersome, inflexible, and sometimes even fuzzy. The authorities' limited opportunities for negotiation is often perceived to stand in the way of the good business. How far-reaching environmental and social requirements may be imposed, particularly in relation to EU legislation is also surrounded by question marks. Furthermore, there is ambiguity in the extent to which individuals' specific needs and choices can be considered.

The large number of trials leads to delays and additional expenses and not infrequently to difficulties in providing essential public services. The fear that the procurement process may be stopped makes the stakeholders avoid more complex approaches which would be to the advantage of the good business.

The prescribed requirements are rarely followed up which make the authorities not to know if they got what they agreed and paid for. Inadequate follow-up is considered e.g. to be an important factor behind the scandals that in recent years was detected in different fields (e.g. elderly care). For conscientious providers, the lack of follow-up often leads to frustration and that they sometimes refrain from participating in tenders. When the contract is not followed up, the opportunities to learn for future procurements will also be reduced.

Small contracting authorities and suppliers are faced with special challenges, both due to resource and skill shortages, and also because the transaction costs associated with the procurement thrash small contracting organisations.

Guidance and other support measures from the central level are perceived as insufficient. They are not always harmonised but they are sometimes kept excessively general. Especially small contracting authorities experience difficulty that in an individual procurement apply and interweave guidance from various procurement supporting organisations. The state procurement support even needs to be developed and put more emphasis on procurement's strategic and economic dimensions.

After investigating and analysing the current situation, the procurement committee's recommendations to the
Swedish Government were that the government should prepare a strategic action plan for good public business and submit to the parliament. The main objective of the action plan has to be governance and control of the public procurement towards better quality and efficiency with the following highlights:

- $\quad$ Public procurement with a focus on leadership and strategy needs to be integrated into skill development of managers/leaders in the state organisations

- $\quad$ Three professorships need to be set up in public procurement. This has to be in juridical science, economics and social science and commissioned training needs to be provided in these fields

- $\quad$ Funding for research on public procurement needs to be increased by 10 to 15 million Swedish Kronor (SEK) annually and interdisciplinary projects should be prioritised

- The responsibility for developing guidelines and information efforts on the procurement's strategic importance should be given to a state-run coordinated procurement support committee, and the committee needs to develop specific guidelines for collaborative procurement

With the procurement of goods and services that are strategic for the welfare, the quality issues should be prioritised on both national and agency/authority level. The coordinated procurement support committee should be responsible for the development of a particular category of product support, whose role is to facilitate the procurement process on the agency/authority level. the aims should be to provide guidelines and support in specific and frequent product categories in terms of needs and market analysis, how quality requirements can be formulated, evaluated and be followed-up/monitored, how the inquiry specifications and contracts can be designed to stimulate quality improvement, how environmental and social criteria can be designed and monitored, how small and medium-sized companies (but also the non-profit/non-governmental sector) can be involved and how innovative solutions can be stimulated, and authorities are prompted to select high and well- thought out requirements (if possible from a functional character to stimulate innovative solutions) and in the evaluation stage reward solutions that go beyond the requirements. Creating incentives in remuneration for suppliers that stimulate further increase of both quality and efficiency during the contract period is also a central importance.

The final report also argues that rule-changes in the following directions should have the highest priority:

- Increased space for dialogue and negotiation

- Higher monetary limits for direct procurement

- Increased possibilities in order to take the individuals' needs and choices into account within the framework agreements in which all the terms are stated/defined

- $\quad$ More efficient testing of procurement objectives 
and a new conciliation mechanism

- Environmentally and socially responsible procurement

- A new procurement authority

From the theoretical discussions above it can however be seen that one aspect is missing in these discussions and that is the possibility to use more long term option-based contracts where a client can prolong the contract with the current supplier/provider/contractor if services are delivered in a satisfactory way.

\section{Material and Method}

\subsection{Empirical Studies and their Main Results}

In order to get insight into public procurement process and contracting of winter road maintenance services a number of empirical investigations was undertaken in three stages as follow:

- Stage one: domestic investigations

- Stage two: international investigations

- Stage three: regional and local investigations

The investigation procedure is described in the following sub-sections.

\subsection{Domestic Investigations}

The first stage was conducted in May 2010 by a questionnaire survey sent to both client organisations and contracting companies across Sweden. An electronic questionnaire was designed with a total of 70 questions divided into four sections. Every section had own theme such as general questions about the participants' background, procurement and contract etc. It consisted of both open-ended answers and multiple choice answers. Only the theme procurement and contract was deemed to be relevant in this context to be analysed.

The selection of participants for responding the questionnaire was partly made with assistance of the STA and partly by other sources. Totally 18 client organisations and contracting companies across Sweden were selected and 41 questionnaires were sent out to the selected targets. The response rate after two reminders was $56 \%$ i.e. 23 responses.

During the first stage semi-structured interviews was also carried out to get additional information. A number of people who were working with winter road maintenance issues were invited to participate to an interview by telephone and e-mail stating the purpose of the interviews and theirs anonymity. All together 12 of them gave their consent prior to the interviews. The participants in the interviews did not participate in the questionnaire survey. More information about the survey is presented in [2].

\subsubsection{Highlights of the Domestic Investigations and Additional Interviews}

The core questions concerning procurement in both questionnaire survey and interviews were about the degree of respondents' satisfaction with the last procurement, number of submitted tenders and evaluation and selection of tenders.

The investigation revealed an imprecise dissatisfaction with the performance of winter road maintenance in all stages across the country i.e. from procurement to outsourcing and performance.

Due to area-wise procurement of road maintenance services, the investigation revealed that the entire procurement process differs from one maintenance area to the other. In some areas it takes more than one year and in other areas it only takes a couple of months the whole procurement procedure in case there are no appeals otherwise this period may be extended depending on the legal process. Even the number of submitted tenders varies from 1 to 8 tenders by area.

The investigation indicates that one reason for the dissatisfaction with the procurement is that the entire process i.e. from the preparation of inquiry specification, tender documents to the procurement of all services and finally signing the contract is performed by the procurement department consisting of procurement officers, economists, and legal officers independently from other involved departments. Some of the procurement professionals are consulting officers that are hired by the client organisations. The results also indicate that during the process, the technical officers or operation managers have a limited influence on the content and design of the tender documents. The survey shows further all the submitted tenders are evaluated and selected on the basis of lowest price. There is a lack of significant requirements of the skills in the procurement documents and finally, several activities connected to the basic road maintenance package are separately procured e.g. measurement of road surface unevenness.

\subsection{International Investigations}

Findings from the domestic investigations concerning procurement of road maintenance including winter measures, made an international investigation and benchmarking essential in order to find out whether there is any similarities or differences between Swedish procurement and contracting procedure and methods with other countries. The main purpose and focus of the international benchmarking was to collect experiences from countries that have similar winter road conditions as Sweden.

The international study was carried out through an electronic questionnaire and interviews with people who work with similar issues in other countries. In the same way as in the domestic investigations, the core questions concerning procurement in the questionnaire survey was, the degree of satisfaction with the last procurement, number of submitted tenders, evaluation and criteria for selection of tenders. Similar to the domestic investigations, in May 2012 an electronic questionnaire was designed with different themes such as procurement. The questionnaire 
consisted of 43 questions with both open-ended answers and multiple choice answers. Totally 12 persons at some Road and Transport Authorities (RTA) around the world were selected to receive the questionnaires (USA; Washington DC, Canada; Ontario, Finland, Norway, Iceland, Denmark, Estonia, Lithuania, Latvia, England, Austria, Japan). The selection of countries for responding the questionnaire was also made with assistance of STA. The response rate after two reminder was $75 \%$ i.e. 9 responses. Seven of the twelve RTA which had been requested for information completely responded to the questionnaire after two reminders and two RTA partly responded to the request to the questionnaire. This stage was also carried out by semi-structured interviews. The investigation was run over a period of three months. More information about the questionnaire can be found in [27].

\subsubsection{Highlights of the International Questionnaire}

According to the international investigation there is a general satisfaction with the performance of winter road maintenance in all stages among all the responding countries i.e. from procurement to outsourcing.

The results from the international survey show that all the responding RTAs perform road maintenance services through public procurement and hiring independent contractors. Summer and winter road maintenance services are integrated in one contract in all countries except one. This implies that all necessary services which have to be performed for an accessible, available and safe traffic during winter, are already stated in the inquiry specification when procuring the services. When asked if it would not be better to procure winter services unbundled, a great majority of the respondents state that they do not see any advantages in procuring winter services separately.

One of the responding RTA (Denmark) performs road maintenance services partly by procuring from independent contractors and partly in-house. Winter road maintenance services are performed as integrated in other road maintenance services in both outsourced and in-house cases. According to the response from Lithuanian Road Administration, performance of winter road maintenance measures are included in the all-year maintenance of the road network and the performance of the measures are the responsibility of Lithuanian's state contractor companies even if it is considered as in-house performance. Only the Icelandic Road Administration procures winter road maintenance services unbundled. All the responding RTAs state that separate procuring, outsourcing and contracting out the winter maintenance services do not imply/give any benefits to their organisations. The Icelandic Road Administration entirely disagrees with a separate procurement and contract of winter services too, even if these services are currently procured separately in Iceland. Denmark and Lithuania also state that procuring winter services separately have not any benefits although they perform the services in-house.

As the survey shows, normally the period of a procurement process is between one and six months from the starting point to a signed contract in all responding countries in case there are no appeals otherwise this period may be extended depending on the legal process. It must be mentioned that the process period is only for those RTA which procure winter services publicly. The number of received tenders with the latest procurement concerning road maintenance varies from country to country and 2 to 8 tenders but in average it was 3 tenders. The awarded contract period varies from three to ten years and in some cases it is longer than ten years. As the study shows some responding countries believe that longer contract period gives opportunity for contractors to be involved and engaged in the content of the contract and provide more scope for contractor innovation. When asked about the criterion for selection of a tender, all the responses were the lowest price tender. Even Denmark and Lithuania which partly and entirely perform winter maintenance in-house, consider lowest price tender for choosing one. Only Finnish Transport Administration (FTA) states that they consider other criteria i.e. lowest price tender plus the quality but the requirements for the quality of the performed work are not specified. According to the responses from all respondents, all the criteria for selecting a tender is stated in the inquiry specification. When asked about the statement - When procuring, the lowest price tender has great importancealmost all the respondents are either fully agree $(57.1 \%)$ or partly agree $(42.9 \%)$.

Some comments in this connection from the respondents:

- Because of the low budget, price is of course important but the quality is more important

- We must first meet the technical criteria and then it must be lowest price

- Totally agree with the statement only if the quality of the requested services are clearly provided and described in the procurement specification

When asking about the statement - When choosing a tender based on lowest price "there will often be problems with the quality" - no respondent is totally agree with the statement but $57,1 \%$ of the respondents is partly agree with the statement and $42.9 \%$ are disagree with the statement followed by some comments. The motivation of the respondents who only partly agree with the statement is:

- There is some correlation between low price and problem with the quality but not always

- It happens that there will be problems with the quality but not always

The respondents who entirely disagree with the statement motivate their disagreement as follow:

- In any case, a contractor will try to do as little as possible and at the same time get as much money as possible. Therefore quality criteria are set, among these are meeting the ISO 9001 standard related to quality system

- ISO standard requirements and agency contract oversight system with the financial penalties ensure that quality standards are met 


\subsubsection{International Interviews and the Highlights}

In the early June 2012, an International Road Congress was held in Iceland. The first author then had the opportunity to meet a number of people from other participating countries in the Congress who work with winter issues. Some participants in the Congress from countries with similar winter road conditions to Sweden were contacted and asked if they possibly could participate in a semi-structured interview. The criterion for invitation to an interview was that they should have had experience in procurement, contract and winter road maintenance. The prospective interviewees were informed about an on-going winter road maintenance research project in Sweden at the Royal Institute of Technology - KTH. The objective of the project was also described to the candidates. When they received information about the aim of the project and they were ensured that the interview would be entirely confidential and no name would be published, some of them gave their consent to participate in an informal and short interview. The interviews were carried out during a week stay in Iceland. The participants in the interview were from Iceland $(n=3)$, Norway $(n=2)$, Denmark $(n=1)$, Finland $(n=2)$ and Lithuania $(n=1)$.

The main outcome of the interviews was about the reorganising and renewals that affect the entire organisations. Skilled staff leaves the organisations to other employers as a consequence and high scale of retirements and the difficulties the client organisations meet with recruitment of appropriate competence. Some of the interviewees highlight an overall hidden dissatisfaction among remaining staff partly due to the lack of skilled staff in all the interviewees' countries which in turn affects the organisations in all categories and stages. Meeting and solving such problems regardless of performing winter maintenance in-house or by procuring publicly in absence of skilled staff is much more complicated than how the road administrations perform winter services.

The road administrations are forced to hire external consultants in order to perform the tasks which cause increased costs even during procurement stage.

According to some of the interviewees, a majority of the externally hired consultants are not as skilled as the ordinary staff that left the organisations both as retired and through changing the job. On the other hand in the interviewees' countries all road maintenance services are procured publicly with lowest price tender as criterion for selection of tenders. As the interviews show, political pressures, lack of skilled staff, high cost of external consultants and lack of inter-organisational cooperation affect the quality of performed work and make all maintenance costs more expensive both in short and long terms.

\subsection{Swedish Case Study - Regional and Area-wise Investigations}

This last empirical investigation was carried out as a case study in order to get more detailed information. The study was run over a period of 5 months between $1^{\text {th }}$ of December 2012 and $30^{\text {th }}$ of April 2013. The investigation consisted of a minor questionnaire survey on area level, interviews with area managers and participatory observations on regional level.

\subsubsection{Area-wise Maintenance Contract Model}

The Swedish road network is divided into six regions; Northern, Middle, Western, Sothern, Eastern and Stockholm region. Every region in turn is divided into a number of maintenance areas. All together there are 115 geographic maintenance areas across Sweden for the state roads. A maintenance area in average comprises between 700 and 1000 kilometres roads. All the operation and maintenance activities are procured and contracted out through competitive bidding in accordance with the EU procurement rules transposed into Swedish general or classic sector.

A routine maintenance package contract, called Basic Operation and Maintenance Package (Swedish: Grundpaket Drift - GPD) is procured area-wise. The contractor for each maintenance area is selected on a price - and quality basis. The contract-awarded contractors are responsible for yearround-maintenance of the roads belonging to each maintenance area. The duration of a contract varies from 3 to 6 years with an option to extend it in one to two more years $(1+1$ year). The contract primarily consists of shortterm measures aimed to keep the roads open for traffic accessibility. The main tasks are maintenance of gravel roads and paved roads, repair of minor road surface damages and potholes, maintenance of rest areas, replacement of damaged road signs and clearing and haymaking of road embankments. Winter maintenance which is a part of this package and is procured inclusively comprises those tasks that must be performed during winter season $\left(1^{\text {th }}\right.$ October $-30^{\text {th }}$ April $)$ to ensure traffic safety for road-users during winter. The main tasks for winter maintenance are snow ploughing, de-icing, salting, sanding and cleaning the traffic signs from snow and carrying out specific maintenance measures for designated objects [17, $28]$.

A road maintenance contract normally consists of different directing and supporting documents such as procurement regulations, description of standards, rules on measuring and payment, etc. The documents are available to all the bidders who want to submit tender.

\subsubsection{The Väsby maintenance Area-Characteristics}

In order to gain insights into area-wise procurement process, the Väsby maintenance area which is one of the ten maintenance areas within Stockholm region was selected to study. Fig. 2 illustrates the location of all maintenance areas within Stockholm region. 

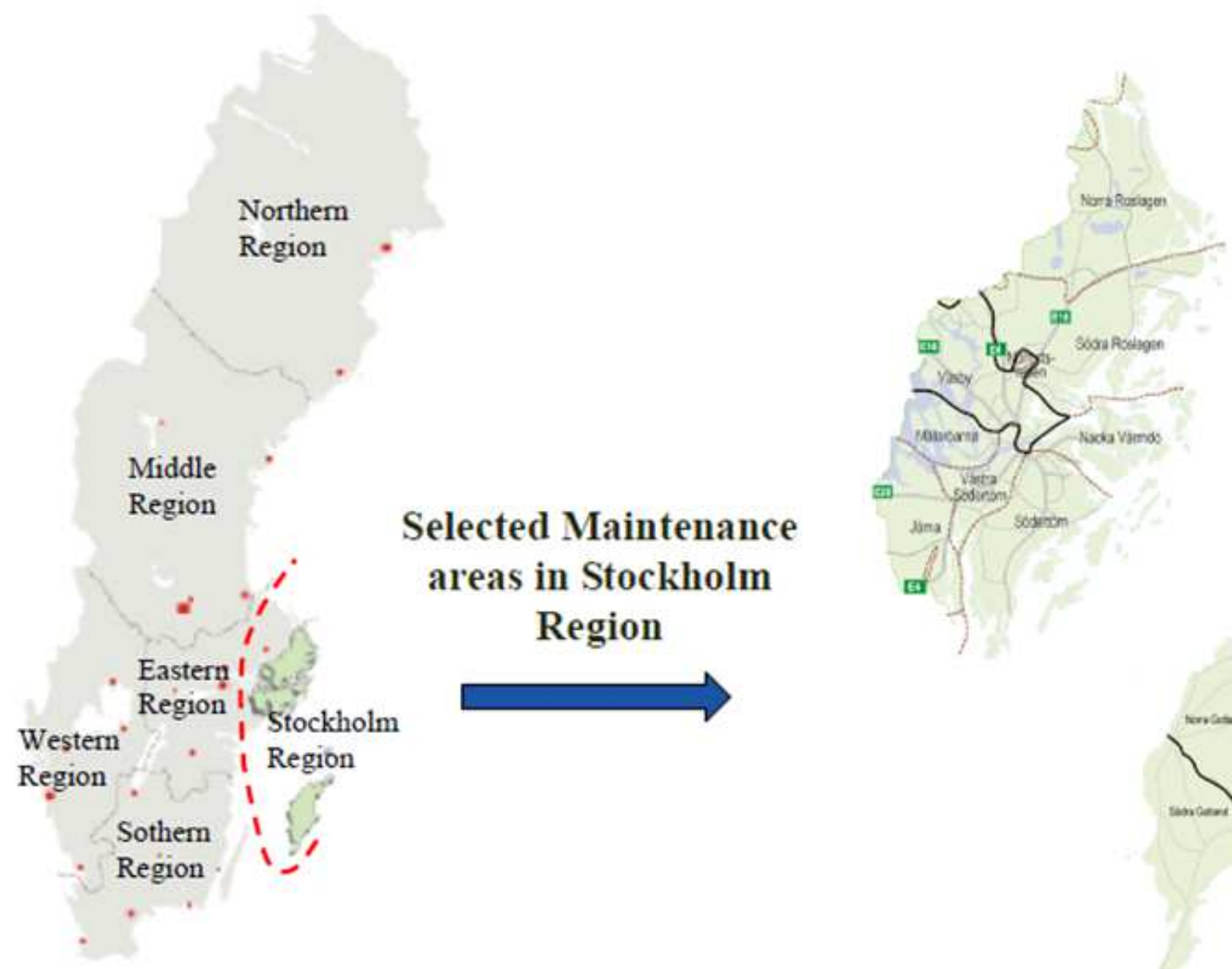

Figure 2. The map of ten maintenance areas within Stockholm region

The reason for selecting the Väsby area is partly as it is located in the Stockholm region. It is also interesting to study because the area is characterized by very high intensive traffic of some large and complex under construction infrastructure projects in daily heavy traffic environment. The two European highways E4 and E18 run through the area. These highways represent the main artery of traffic from Stockholm towards north to the Sweden's largest and main airport (Arlanda), the fourth Swedish largest city (Uppsala) and towards west to the other larger cities. The area is also characterized by very heavily exploited with large residential complexes and several major shopping centres. The maintenance area serves as passage for approximately 100000-150000 vehicles per day. Many of these vehicles are for the transport of cargo or coaches with tourists, airport buses with passengers back and forth to the airport etc. As it is typical for case studies the aim is not to find general results. The primary aim is to get information from an interesting case that can be usual for a more general discussion of different policy options. As the Swedish road network is rated in road classes from 1 to 5 according to the traffic flow (Annual Average Daily Traffic - AADT) of the roads, within Väsby area almost 500 $\mathrm{km}$ roads run with different road classes as the following table shows.

Table 2. Classification of roads and their length within Väsby area [After 29]

\begin{tabular}{lll}
\hline $\begin{array}{l}\text { Traffic flow } \\
(A A D T)\end{array}$ & Road class & $\begin{array}{l}\text { Road length } \\
\mathrm{Km}\end{array}$ \\
\hline$>\mathbf{1 6 0 0 0}$ & 1 & 302 \\
$\mathbf{8 0 0 0 - 1 6 0 0 0}$ & 2 & 94 \\
$\mathbf{2 0 0 0 - 7 9 9 9}$ & 3 & 65 \\
$\mathbf{5 0 0 - 1 9 9 9}$ & 4 & 9 \\
$<\mathbf{5 0 0}$ & 5 & 36 \\
\hline
\end{tabular}

Commuting through the area to the city centre on the rush hours is very extensive, often with long queues as a result. Sometimes the traffic can seem almost to be totally standstill. Fig. 3 shows complexity of the selected area in more details. 


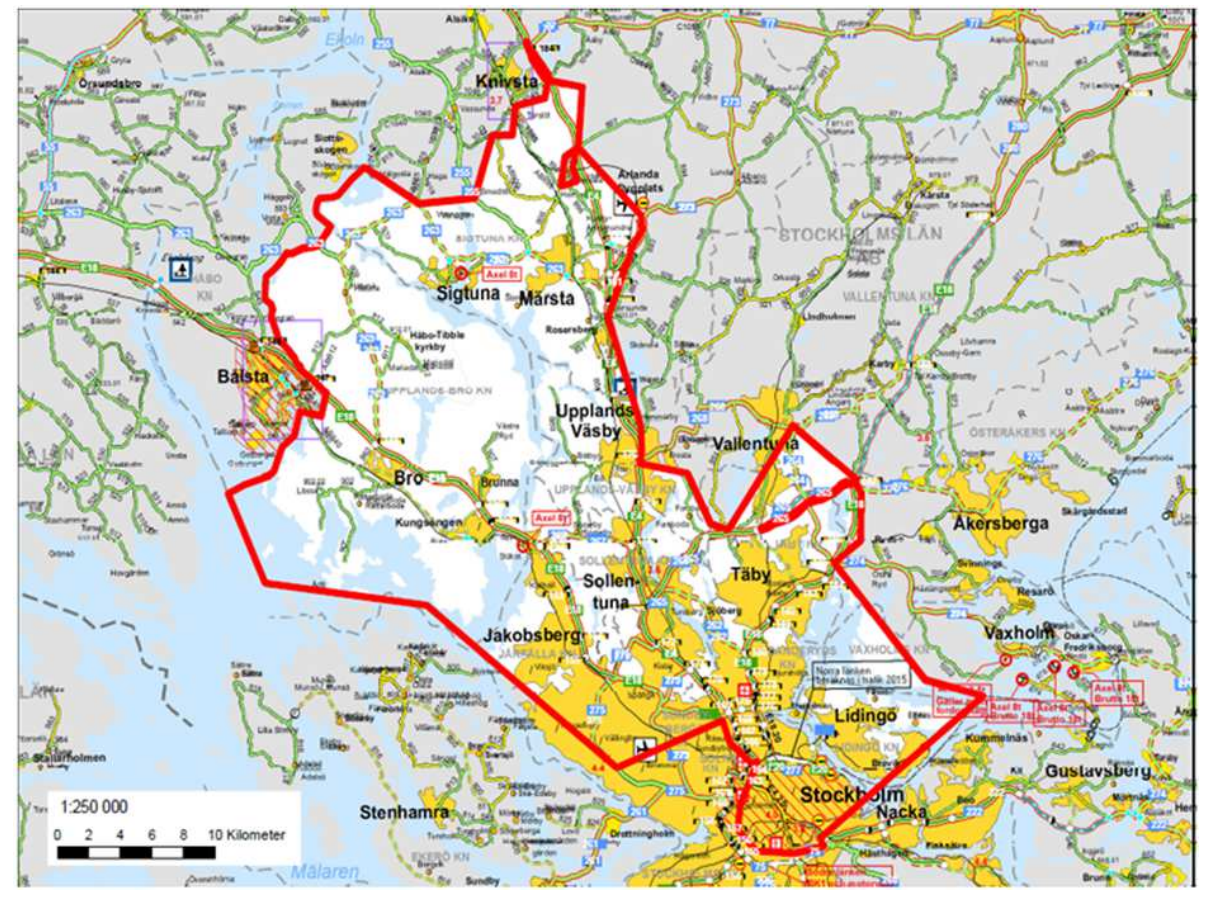

Figure3. Detail map of Väsby maintenance area [After 29]

Performing maintenance services of public roads within this area is affected by the character of the area. Very high traffic intensity puts high demands on both the client and contractors in terms of just-in-time maintenance during harsh winters. Most of the planned maintenance has to be performed at night. Working in such complex infrastructure systems requires very accurate and careful coordination and planning before starting necessary measures on the roads within this highly loaded area.

\subsubsection{Contract Model Used in the Väsby Maintenance Area}

The basic maintenance package is also applied for this area as the standard document for procurement of the road maintenance services. The contract model used in this maintenance area is called total contract with a description as turnkey contract for the execution of the operation and maintenance of public roads within Väsby maintenance area. The act on public Procurement is also applied for procurement and the contract is awarded in accordance with those regulations in the act that apply over the thresholds.

\subsubsection{Questionnaire Survey, Interviews and Participatory Observation}

The imprecise dissatisfaction with procurement of road maintenance found in earlier investigation on the national level and a lack of significant improvements of procurement methods during the past three years (since the project started 2010), made a new investigation on the area level essential. In March 2013, a minor questionnaire survey was conducted to explore and find out why there are still dissatisfactions with both procurement and outsourcing of the road maintenance including winter services. The questionnaire consisted of 11 questions. The major theme of the questionnaire was the procurement process with only open-ended answers and sent to the project managers and site managers responsible for performance of road maintenance services in the Väsby maintenance area within Stockholm region. In addition to the questionnaire survey, the investigation included interviews with all client's project managers and contractor's site managers within Stockholm region's ten maintenance areas. Pending responses from the questionnaire survey, a number of project managers and site managers within Stockholm region were contacted and were asked about possible interviews. The purpose of interviews was described for the prospective interviewees. After ensuring them that the interviews would be entirely confidential, the interviews were performed during April 2013.The aim of interviews was to get deeper understanding about the problematic issues concerning procurement procedure and contract.

Parallel to the questionnaire and interviews, a participatory observation was performed over a period of five months (December 2012 - April 2013) by attending as neutral listener in the monthly meetings. The aim of the participatory observation was to get insight into the discussions between the client's and contractor's delegates in the meetings and later on review the meeting protocols.

\subsubsection{Highlights of the Regional Investigations}

After receiving all the responses from the questionnaire survey, compiling the interviews and reviewing the monthly meeting protocols, the result of the investigations can be summarised as follow:

The procurement process of new contract for the selected 
maintenance area began in May 2011. The time for preparing the procurement documents was inadequate because the documents had to be prepared by the project managers which were not their duties and were perceived as extra workload with respect to the other daily tasks. The inquiry specifications were accessible to tenderers in January 2012 and the contract was signed in April 2012. As the respondents state the procurement was a very long process. The current contract price for the investigated area is 147000000 SEK over a four years period with possibility to prolong for two more years as option. Approximately $42 \%$ of the contract sum is allocated for winter maintenance tasks in case of a normal winter otherwise it increases to even higher percentage of the contract sum. Only two tenders were submitted and both the bidders were established companies. The difference between the two submitted tenders was $25 \%$ i.e. the contractor which was awarded the contract had submitted tender with $25 \%$ lower contract price than the other. The contractor was the same that already had current contract. The contract contains items with "variable quantities" where the bid consists of a price per unit and the bid is calculated given an assumed quantity. As analysed in [16] this opens up for tactical bidding where a low price is given for quantities that is believed to be overestimated and high prices for quantities that the bidder thinks is underestimated. This means that the "real" differences in costs between the bids are difficult to know in advance.

As Väsby maintenance area is characterised by very high intensive traffic and by some large and complex under construction infrastructure projects in daily heavy traffic environment, this complexity has major impact on performance of winter road maintenance within the area e.g. along with E18 motorway within the area, performance of winter road maintenance measures were affected due to lack of turning possibilities for ploughing trucks and obstructions caused by concrete element barriers. The obstacles not only affected the rational ploughing but also increased the maintenance costs with 1.2 million SEK extra costs during winter 2012-2013, because such situations are not covered in the contract.

The new more pure administrative client organisation approach which gives more responsibility to the contractors limits the responsible project managers possibility to follow up the performed services in the field to an adequate extend. All performed services have to be inspected and verified by a so-called publicly procured third-party inspection/control that has indirect impact on continuous winter maintenance.

As the local investigation shows, four of ten maintenance areas within the selected region have either got new road maintenance contract or have planned to procure the road maintenance services during 2013.Those areas that still have a valid contract the procurement of new contract is under process and it is difficult to predict how long the procurement process takes with respect to the lack of skilled personnel. Next procuring time for the rest of areas is planned to be performed during 2014 and 2016 due to valid current contract.

The new contracts do not take the soft parameters into consideration in the procurement process. Road surface unevenness measurement (International Roughness Index IRI) is performed once a year on the roads with high traffic flow and every five years on the roads with low traffic flow (see table 2).These services are procured separately and centrally as framework agreement that is valid for the whole Sweden. The starting point for the measurements of the road surface unevenness varies depending on when the suborder for implementation is done.

Contractors often have smart solutions but such proposals are not taken in the inquiry specifications i.e. innovative solutions are not procured by the client. Thus the innovative measures are not acceptable due to limitations in the contract.

The participatory observation also reveals another problem area that is operation and maintenance of weather stations (Road Weather Information System - RWIS) within the whole Stockholm region's ten maintenance areas. Although the weather stations have a key role in planning of winter road measures, maintenance of these assistive tools like IRI are procured apart from the area maintenance contracts also as framework agreement. Development and upgrading of the weather stations are even procured separately as commission contract under a certain period.

The three above named service categories that are procured separately have different contract period with different procurement process which are not in step with each other and nor the road maintenance contract.

As the participants in the regional investigation responded, different procurement process, separate framework agreements and contracts that are practically related to each other affect both the maintenance costs and the quality of the performed services. As some respondents experience the lack of coordination between several scheduled tasks that have connection with winter services affects winter maintenance activities. It is perceived to be due to several individual contracts with different procurement duration. This is discussed in more detail in [17] where it is recommended that these additional tasks are included in the basic contract.

\section{Analysis, Discussion and Recommendations}

\subsection{Analysis and Discussion}

Final users' dissatisfaction is usually a measure that indicates if the quality of goods and services meets their expectations or not. As $[30,31]$ state, complaints are the indicator or measure of the quality of goods or performed services. In other words end-users' dissatisfaction and complaint are such indication of shortages in the selected methods which conventionally are used for procurement of goods and services. The indication of shortfalls in most cases can provide valuable information that helps decision- 
makers see and highlight the deficiencies in the selected procurement methods and change them that had resulted in improper contracts.

In addition to winter maintenance services which are integrated in the Basic Operation and Maintenance Package, there are several other agreements and contracts that are publicly procured for other road purposes. These agreements are called framework agreements with different duration and intended to perform different road tasks. Under duration of these framework agreements the contract-awarded contractors or consulting companies do not start performing the tasks before a written and formal suborder is given. This implies that there is often risk for lack of coordination on performing one or more tasks even related to the winter maintenance i.e. the performance of the tasks are not in step with each other. As the investigations reveal, none of these services are procured and contracted out bundled or cooperatively. A number of these contracts are for performance of some services that have direct connection to winter road maintenance service which are not included in the winter maintenance package contract.

As we explored, the current road maintenance contract is already bundled but in a questionable way. As [11] states, contract bundling may reduce or eliminate the government's pricing benefits due to limited competition. According to the results of our study in Väsby maintenance area the competitive bidding was already limited as there were only two tenders per maintenance area. The limitation in competitive bidding when the winter services were procured indicates an improper contract bundling. In our case, [11]'s discussion on contract bundling can be interpreted as if winter road services are procured and contracted in a manner in which right services are bundled, the impact of contract bundling on competitive bidding are eliminated or marginalised.

Some of the framework agreements are intended for measurement of road surface unevenness (IRI), maintenance of weather stations (RWIS) and development and upgrading of software used in weather stations, and even third-party verification and inspection framework agreement.

In Väsby maintenance area as the study shows the procurement and renewal of the basic maintenance package contract was a long process and took long time over a year. When the procurement process takes so long time there is often risk for performing the maintenance tasks without any valid contract due to the currently valid contract period would almost be finished before the new one comes to force.

The problems with the new contract in terms of getting the right things performed and the right incentives for the contractor can be that the responsible project managers are not allowed to inspect the places where the tasks are performed. The project managers are not allowed to visit places in a sufficient extent either. The strategy of being a "Pure client" is in this way negative for the development of the client organisation. Inspecting and verifying the performed tasks by third-party controllers implies that the client organisations transfer all direct information about the statues of the road infrastructure to the third-party organisation.

As the international survey shows (sec. 5.2.1) according to the Canadian (Ontario) experiences a long contract period creates incentives for contractors to increase their knowledge of the contract area and to be more innovative. A four-year contract period with option for extension in two more years is too short for contractors to do this. Longer time period with option to cancel and/or with more generous option to renew the contract creates incentives for contractors to develop their own organisation and also to develop the cooperation with the client.

As the study reveals maintenance of weather stations (RWIS) is procured separately leading to a separate framework agreement, see e.g. [32]. Due to the separate procurement and lack of cooperative maintenance of these assistive tools the maintenance activities are almost delayed that in turn affects the winter road maintenance services with unnecessary increased costs.

\subsection{Proposal to Improvement}

As [33] argues, in order to discuss the benefits of bundling services at the first step the disadvantages of unbundling should be explored. When several agreements and contracts with connected contents are procured separately it causes dissatisfactions as consequence. Reference [34] studied the pros and cons of unbundled vs. bundled administrative services and realised that one of the perceived disadvantages of unbundled is that there are too many parties involved in the process. As [10] studied, when bundling different activities within construction area, financial aspects, risk allocation and life cycle cost should be taken into consideration as three central aspects.

One preliminary proposal in order to eliminate the deficiencies in procurement procedure can be that the activities that have connection to each other are bundled.

As our study shows, since different duration on procurement process, several contracts for performing different tasks for the same purpose and different starting time to perform the tasks and finally lack of cooperation between the contract-awarded contractors affect winter road maintenance significantly and cause unnecessary increased costs. Bundling of all the contracts which have connection to winter maintenance into an integrated contract could be a proposal to make the performance of winter road tasks more efficient and reduce maintenance costs.

While performance of winter road maintenance tasks are currently integrated in an all-year-round road maintenance contract and the results of the empirical investigations reveal, there are at least three service categories with direct connection to winter road maintenance tasks that are procured separately with individual contract as framework agreements. These service categories are namely 
measurement of road surface unevenness, repair and maintenance of weather stations and development and upgrade of weather stations. In addition to these three contracts there is additional contract for inspection and verification of the performed services. To reset and adjust road surface defects after measurement of unevenness is even procured separately.

With respect to [10]'s three central aspects in bundling activities, it could be argued that bundled procurement of different activities in winter road maintenance as the advantage in that it creates a multi-disciplinary skilled organisation where all winter maintenance related skills are brought together.

As mentioned in [12], client organisations may either procure separate minor bundles for closely related groups of services or with procurement of large and comprehensive bundle of services, they can pursue a strategic alliance a so called partnering concept with their potential contractors in order to eliminate or minimise the risks.

As we show in our study, the current basic winter road maintenance package contract runs as bundle service contract including a number of tasks. The main procured tasks are maintenance of gravel and paved roads, repair of minor road surface damages and potholes etc. winter maintenance tasks are integrated in the package and comprises the tasks that must be performed during winter season. When studying the task items in the contract we realise that even it is a bundle of different tasks, there is not bundled in closely related groups of services. On the other side as mentioned earlier there are other services related to winter issues that are separately procured and performed through separate contracts such as IRI, RWIS, third-party inspection and more.

\subsection{Incentive Model}

Reference [35] states that due to at least partly ineffective contract structure, several construction contracts and compensation structures often ignore or mistake what motivates people who perform the work.

As our study shows, winter maintenance services are procured and contracted out without any bonus system as economic motivation or incentives that can significantly motivate effective performance of winter services. Reference [36] states in this connection that contracts should create such economic motivations or incentives that result in some kind of rewards and takes three incentive models into consideration namely; cost, time and performance incentives. But [36] claims that even contractors are actually driven by many other incentives in their activities e.g. good relations with clients, agencies, employees, capital supply and safe and secured long-term development, cost incentives are preferable in construction industry.

A primary goal which usually also constitutes a prerequisite for other milestones, is to maximise profits alternatively where appropriate to limit the causalities. A contract with cost incentives aims at increasing the contractor's profits in relation to the cost savings that can be achieved. Due to lack of bonus system in the current contracts, in order to make the services more cost effective we propose an appropriate bonus system be procured. A bonus system as advantage creates time and performance incentives which in turn give contractors opportunity to organise their workforce in an effective manner to reach the clients' requirements. A very strong incentive in many contexts is that good performance in one contract leads to more contracts in the future. Reference [37] writes "One of the great achievements of game theory is that it provides a framework for understanding how such a reputation mechanism can support cooperation". This means that "soft parameters" related to earlier performance is important when procurement for later periods are carried out.

As we showed in our earlier studies application of partnering concept (see [17] for more details) with procurement and contracting of winter maintenance services minimise or eliminate dissatisfactions. A rather detailed contract can in a certain extend be good but a partnering model for procurement creates such situations that adjustments can be made in a smooth way during the contract period. When procuring winter road maintenance services we propose application of partnering combined with bundling of proper closely related services as a prime solution to make winter road maintenance services more effective.

When procuring winter road activities through application of contract bundling model together with partnering concept, the model as advantage can also create better documentation of how things worked and work, and competence and track records will be more important and [36]'s three incentive models are fulfilled.

According to [12], significant benefits in the form of improved performance and reduced costs can be provided associated with a bundled service contract.

Selection of bundling method together with partnering concept into an integrated single contract in order to reach improved performance of winter services requires that at the first step winter road maintenance tasks are broken out from the current basic maintenance package. Meanwhile [12] discusses which/what potential benefits both client organisations and contractors/suppliers can expect associated with bundled service contract by procuring related services they even warn for the potential risks to client organisation e.g. if a bundle consists of a broad set of services that exceed potential contractors' capability and capacity then the client has to run the risk of receiving poor quality of the performed tasks and deal with unnecessary increased costs. One additional risk is that some contractors do not participate in bidding. According to our study all the 115 maintenance areas are not as complex as Väsby maintenance area thus the general proposal of the study is that before merging all the contracts to a single one, a feasibility study is also required in order to see the possibilities for a bundled procurement of all these services 
i.e. an assessment based on each area's prerequisite/precondition is required due to different level of complexity in the maintenance areas.

\section{Conclusions}

This study focuses on the procurement process and contracting out the winter road maintenance with the aim of providing deeper knowledge and understanding of the way selected Road and Transport Administrations within EU procure and contract out winter road maintenance services particularly in Sweden. In this study we have found that there are differences between procurement processes in different maintenance areas.

The study also shows that there is only a slight difference between some EU member state's road authorities in how they provide winter maintenance services. Even in Norway as a non-EU member, the procurement procedure and method do not differ significantly from the other EU members that have to follow the EU directive and public procurement rules. A speculation to this could be that the Norwegian procurement method has indirectly been influenced by EU laws due to Nordic cooperation within transport sector. Benchmarking of the set of practices in a number of European countries and North America concerning procurement and outsourcing winter road maintenance services integrated in a single contract shows a significant difference in the length of the contract period. Almost all contracts are procured for a shorter period in EU. The significant differences in the countries' we investigated and studied is that the European countries' and the North American countries' procurement and contract model could be due to the differences between the degree of flexibility in the legislations and law of public procurement in these countries. As the study shows the current dissatisfaction in both Sweden and the UK is an indication of either the inflexibility in EU directive or excessive interpretation of EU procurement rules in every member country. As our study reveals there is a widespread dissatisfaction with the Swedish procurement method within Swedish construction industry. As concluding remarks we believe in the need of a review of the Swedish act on public procurement that stems from EU directive and public procurement rules in order to create long term functional and flexible contract within Swedish construction industry.

The theoretical and empirical investigations indicate that procuring and contracting related services can be improved in the following way within the current legal framework:

- A special contract for winter maintenance where all winter related services are bundled together

- A partnering structure in the contract where adjustments can be made more smoothly to changing situations

- Inspections are carried out by the client and contractor together as part of the partnering concept

- A bonus system related to overall contract performance, including customer surveys
- $\quad$ Promise that "soft parameters" related to current contract performance will be important when procurement is carried out for the next period.

As a first step it is suggested that systematic pilot tests of this model should be carried out in some maintenance areas in Sweden in order to make a systematic evaluation as was done in the case analysed in [28].

\section{References}

[1] R. Robinson, U. Danielson, and M. Snaith, Road Maintenance Management - Concepts and Systems, MACMILLAN PRESS LTD, London, 2007.

[2] A. Abdi, Technical and Contractual Aspects in Winter Highway and Railway Operation and Maintenance - a survey of current technical system and contract forms in Sweden, Licentiate thesis, Royal Institute of Technology KTH, Stockholm, 2011.

[3] R. Österberg, Contracting Out Public Service, PhD thesis, TRITA-INFRA 03-046. Division of Urban Studies, Royal Institute of Technology - KTH, Stockholm, 2003.

[4] A. Abdi, H. Lind, and B. Birgisson, "Designing appropriate contract for achieving efficient winter road and railway maintenance with high performance quality - a survey of the state of practice in Sweden," International Journal of Quality and Service Sciences."In press".

[5] P. Cousins, R. Lamming, B. Lawson, and B. Squire, Strategic supply management - principals, theories and practice, Prentice Hall, London, 2008.

[6] A. Zeng, "A synthetic study of sourcing strategies," International Management \& Data System, Vol. 100,Iss:5, pp. 219-226, 2000.

[7] I. Titheesawad, and T. Kijboonchoo, The effects of bundle composition, price, framing and familiarity on consumers' purchase intention, MSc thesis, Assumption University, Bangkok, 2003.

[8] S. Stremersch, and G. J. Tellis, "Strategic Bundling of Products and Prices: A New Synthesis for Marketing," Journal of Marketing, Vol. 66, pp. 55-72, January 2002.

[9] J. P. Guiltinan, "The price bundling of services: a normative framework," Journal of Marketing, Vol. 51, pp. 74-85, April 1987.

[10] H. Lind, and L. Borg, "Service-led Construction: is it really the future?" Construction Management and Economics, Vol. 28, No. 11, pp. 1145-1153, 2010.

[11] L. LeClair, "Improper contract bundling hampers growth and viability of small construction firms," Modern Contractor Solutions Journal, Vol. 3, pp. 38-39, April 2009.

[12] L. H. Baldwin, F. Camm, and N. Y. Moore, Federal Contract Bundling: a framework for making and justifying decisions for purchased services, Rand Corporation, Santa Monica, California, 2001.

[13] P. Milgrom, and J. Roberts, Economics, Organisation and Management, Prentice Hall, New Jersey, 1992.

[14] J. M. Lantran, and C. Morse, "Development of private 
sector: framework and competition," Proceedings of the Highway Policy Seminar for Countries of the Former Soviet Union, Moscow, 15-19 May 1995, Washington DC: The World Bank, 169-178, 1995a.

[15] S. Tadelis, "Public procurement design: Lessons from the private sector," International Journal of Industrial Organization, vol. 30, pp. 297-302, 2012.

[16] J. Nyström, Partnering: definition, theory and evaluation. $\mathrm{PhD}$ thesis, Division of Building and Real Estate Economics, Royal Institute of Technology - KTH, Stockholm, 2007.

[17] A. Abdi, H. Lind, and B. Birgisson, "Effective winter highway maintenance through application of partnering concept," International Journal of Economics and Management Engineering, Vol. 3,No. 3, pp. 112-125, 2013.

[18] Swedish Transport Administration - STA, Swedish Transport Administration's Procurement Operations, Borlänge, 2013.

[19] Achilles Information AB, Trans Q - Qualification System for Suppliers to Transport Utilities in Scandinavia, Information Booklet, Stockholm, 2011.

[20] Swedish Act on Public Procurement, SFS 1992:1528 (Svensk författningssamling, Lag om Offentlig Upphandling SFS1992:1528), Stockholm, 1992.

[21] T. Stenbeck, Incentives to innovations in road and rail maintenance and operation, Licentiate thesis, Royal Institute of Technology - KTH, Stockholm, 2004.

[22] Expowera, Public Procurement, viewed 21 March 2013,www.expowera.se

[23] Swedish Competition Authority - SCA, The Swedish Public Procurement Act - an Introduction, ISBN - No. 978-9188566-01-0 (print), E-print AB, Stockholm, 2012.

[24] Official Journal of the European Union, Directive 2004/18/EC of the European Parliament and of the Council of 31 March 2004 on the coordination of procedures for award of public works contracts, public supply contracts and public service contracts, European Parliament, Strasburg, 2004.

[25] Commission of Inquiry, A better deal for public building, report, London, 2012.

[26] Government Offices of Sweden, Good Business: A Strategy for Sustainable Public Procurement, Official Reports of the Swedish Government - SOU 2013:12, final report, Stockholm, 2013.

[27] A. Abdi, Winter Road Maintenance on Contractual Basis An International Benchmarking, Research Rep., Royal Institute of Technology - KTH, Stockholm, 2012a.
[28] H. A. Mattsson, and H. Lind, "Experiences from procurement of integrated bridge maintenance in Sweden," European Journal of Transport and Infrastructure Research, Vol. 9, No. 2, pp. 143-163, 2009.

[29] Swedish Transport Administration, Contract documents for Väsby maintenance area within Stockholm region, 2012.

[30] A. Kouzim, E. Löffler, H. Klages, and K. K. Nada, "Benchmarking and performance measurement in public sector: towards learning for agency effectiveness," International Journal of Public Sector Management, Vol. 12, No. 2, pp. 121-144, 1999.

[31] A. G. A. Ilhaamie, A. A. Zainal, and Z. Yuserrie, "Competency-based pay and service quality: an empirical study of Malaysian Public Organisations," Asian Academy of Management Journal, Vol. 14, No. 1, pp. 21-36, 2009.

[32] A. Abdi, H. Lind, and B. Birgisson, "Use of Road Weather Information System (RWIS) as Assistive Tool for Effective Winter Road Maintenance - Technical and Contractual Interactions," International Journal of Engineering and Technology, Vol. 2, No. 12, pp. 2002-2012, 2012.

[33] K. Ochota, "Benefits of bundling, South Carolina, Captive Review," pp.14-15, 2008. Viewed 1 July 2013, www.captivereview.com

[34] J. D. Carlson, P. Carlson, and R. Viola, "Advantages of Unbundled vs. Bundled," Plan Design Consultants Inc., San Mateo, California, 2008.

[35] J. W. Darrington, and G. A. Howell, "Motivation and incentives in relational contracts," Journal of Financial Management of Property and Construction, Vol. 16, No. 1, pp. 42-51, 2001.

[36] P. Jacobson, Contract and Remuneration forms (Entreprenad- och ersättningsformer), BFAB, Stockholm, 2004.

[37] J. Watson, Strategy: An Introduction to Game Theory, 2nd ed., W. W. Norton \&Company, New York, 2007.

[38] S. Black, S. Briggs, and W. Keogh, "Service quality performance measurement in public/private sector," Managerial Auditing Journal, Vol. 16, No. 7, 400-405, 2001.

[39] J. L. Fuentes-Bargues, and C. Gonzáles-Gaya, "Determination of disproportionate tenders in public procurement," Journal of Investment and Management, Vol. 2, No. 1, pp. 1-9, 2013

[40] T. Ventovuori, "Elements of Sourcing Strategies in FM Services - AMultiple Case Study," International Journal of Strategic Property Management, Vol. 10, pp. 249-267, 2006. 